https://doi.org/10.48009/2_iis_2007_207-213

\title{
INFORMATION TECHNOLOGY INTELLECTUAL PROPERTY ETHICS: ISSUES AND ANALYSIS
}

\author{
Alan R. Peslak, Ph.D., Penn State University, arp14@psu.edu
}

\begin{abstract}
Unethical information technology behavior is estimated to cost billions of dollars of losses for businesses and corporations. This includes issues associated with information technology property. As an example, software piracy is resulting in extremely large costs for IT (information technology) firms. This paper examines current views of information technology property as measured by a series of six current information technology related property ethical issues. The study surveys a cross-section of students, faculty, and professionals and analyzes recognition of an ethical issue for each individual topic. First, the study confirms that all the studied information technology property issues are generally recognized as important ethical topics. Age and gender are studied to determine demographic influences. Significant differences were found by age and gender for some but not all property issues. A discussion and implications of this research are also presented.
\end{abstract}

Keywords: information technology (IT), property, IT ethics, business ethics, intellectual property

\section{INTRODUCTION}

\section{Intellectual Property}

This paper deals with the ethical issues associated with information technology property. A common legal definition of property "includes both real and personal property or any interest therein and means anything that may be the subject of ownership”. (Dorchester County, 2005) Property generally takes two forms - physical and intellectual. Physical property includes all tangible items such as land, housing, or possessions. "Intellectual property represents the property of your mind or intellect. It can be an invention, trademark, original design or the practical application of a good idea. In business terms, this means your proprietary knowledge - a key component of success in business today. It is often the edge that sets successful companies apart and as world markets become increasingly competitive, protecting your intellectual property becomes essential.” (Commonwealth of Australia, 2005) Though many studies have examined ethical positions on intellectual property, little work has been performed on the overall concept of property associated with the information age including hardware, software, data, and communications infrastructure. Kini, H.V. Ramakrishna, B.S. Vijayaraman (2004) and Gupta, Gould, and Pola (2004) deal almost exclusively with software piracy. One of the few studies to examine the importance of more information technology property issues was Calluzzo and Cante (2004), who included in their information ethics survey other aspects of information property. This, then, is a broad study of information technology property including intellectual as well as physical information technology property.

\section{Property rights}

Traditionally, property rights, both physical and intellectual, have been guaranteed in the US and many other countries' constitutions. Even the United Nations in Article 17 of its Universal Declaration of Human Rights (1948) states:

“(1) Everyone has the right to own property alone as well as in association with others.

(2) No one shall be arbitrarily deprived of his property."

Due to the fundamental nature of these rights, the ethical views of individuals on information technology property issues hold important significance. Property in the Information Age is a complex concept involving many diverse topics. Ethical issues that affect information technology property abound. Protecting property rights has become difficult with the rise of intellectual property and the increase in violations of electronic physical property through electronic invaders such as viruses and worms. This report reviews six current information technology property issues and surveys a sample of the population to see if they recognize the importance of ethics related to these issues and/or technologies.

\section{Recognition of an ethical issue}

The recognition of the importance of ethical issues is based on Rest's (1986) multi-step model in ethical decision making. The first step in this process is recognition of an ethical issue. Yuthas and Dillard 
(1999) suggest that the complexity of issues dealing with advanced technology has resulted in unique challenges for ethics development. According to the authors, moral issues are not issues until we "recognize them as such." This work is an attempt to determine the level of recognition and importance of specific property topics as ethical issues, and addresses this first step in the ethical decision making process.

This paper deals exclusively with the first component in Rest's (1986) ethical decision making model, recognizing moral issues. This model is supported by many researchers including Jones (1991) and Harrington (1997) who refined this recognition into "interpretation of the situation or recognition of a moral issue". Recognition of ethical issues is a necessary first step in moral development (Rest, Thoma, and Edwards, 1997) and has been shown to correlate to higher levels of moral development (Sweeney and Roberts, 1997).

\section{MOTIVATION FOR THE STUDY}

The importance of ethical behavior in the use of information technology holds high relevance for both businesses and researchers. Numerous research studies have been performed to assess the influences of various factors on information technology ethical decisions. Peterson (2002, p.346) notes that "identifying factors that contribute to unethical behavior and developing methods of controlling inappropriate behavior in organizations is an area of increasing interest to academicians and practitioners." Laudon (1995) noted the "ethical vacuum" in information technology. Smith and Hasnas (1999) suggest that corporations are instituting many new technologies and information systems initiatives without addressing the ambiguous ethical environment and dangerous behaviors that can result.

The economic impact of unethical IT behavior is staggering. Caluzzo and Cante (2004) note many instances of IT ethics shortcomings. They note surveys that have shown that $45 \%$ of IT professionals acknowledge engaging in unethical behavior. Another study recorded a 69\% acknowledgment rate. They note a 1995 study that suggested worldwide software piracy losses were estimated at $\$ 8$ to 12 billion and a 1999 study that reported that $50 \%$ of all software in use in 1996 was illegally copied. In 1998, they note that $98 \%$ of software in China was illegally copied. Dean (2005) discusses the impact and importance of software piracy and intellectual property violations suggesting a $\$ 64$ billion negative impact on taxes and reduction of 1.5 million jobs due to piracy. Kini, Rominger, and Vijayaraman (2000) demonstrated the pervasive nature of software piracy in the US today.

Understanding the influences on unethical IT behavior can have major returns if addressed. Peterson (2002) notes the importance of improving computer ethics citing many of the recent problems with unethical behavior including software piracy, virus development and illegal access estimated at costing corporations losses of billions of dollars per year. Bass, Barnett, and Brown support the importance of business ethics study suggesting that unethical behavior "costs billions of dollars each year, damages the image of corporate America, and has implications for the legitimacy of our social institutions and the well-being of our society". Banerjee, Cronan, and Jones (1998) note the importance of understanding information technology ethical issues due to their potential in the corporate arena for significant security and productivity losses. They suggest that computer misuse has cost the US billions of dollars per year and note that nearly half of clients surveyed suffered security related losses in the last year. They also note that security measures can have some impact in reducing losses but suggest that individual ethical behavior can be improved. If ethical behavior can be improved, then these losses and crimes can be reduced saving corporations millions if not billions of dollars. They suggest that in order to improve IT ethics, "an overlooked and potentially effective deterrent is the identification of unique and situational characteristics of IS personnel who act ethically/unethically. Identification of unique characteristics could lead to the formulation of more effective ways of solving the problem of unethical use or inappropriate use of computers." They suggest that methods to improve behavior after identification include education and organizational environment.

\section{HYPOTHESES DEVELOPMENT}

There has been considerable research that has found that information technology ethical issues are being recognized by students and professionals alike. Hay, Larres, Oyere, and Fisher (2001) found ethical perceptions of undergraduate students in "computerrelated situations.” Oz (2001) found ethical recognition of IT situations among IT professionals. In the specific area of information technology property, little comprehensive study has been performed. As a result, we propose hypothesis one to confirm the likely scenario that as with other ethical issues, there will be strong recognition of IT property ethical issues among the surveyed population. As 
noted, this paper deals exclusively with the first component in Rest's (1986) ethical decision making model, recognizing moral issues.

Hypothesis 1: Information technology property ethical issues will viewed as important ethical issues.

The exploration of the influences on IT ethical decision making has been shown to be an important goal for this study. Many researchers have studied the impact of age on ethical decision making. Two demographic factors have been shown to sometimes affect ethical decision making - age and gender. Age has often been shown to affect ethical decision making. Vitell (2003) found that older individuals more readily follow ethical norms. As a result, we propose that age will significantly affect views on information technology property issues. To test the effect of age, hypothesis two was developed.

Hypothesis 2: Age will significantly affect recognition of the importance of property ethics issues.

A large body of research has investigated the impact of gender on ethical decision making. Loch and Conger (1996) note "evidence of gender differences in ethical intention formation”. Krete and Cronan (1998) found in all their information technology ethical scenarios that men were "less likely to consider a behavior as unethical”. Hay, Larres, Oyelere, and Fisher (2001) studied the computer related situations and undergraduate students ethical perceptions. The authors noted the significant body of literature that has suggested gender difference in business and IT ethics decisions. Sigma-Mugan, Daly, Onkal, and Kavut (2005) studied the gender influence of ethical sensitivity. We propose that gender will have an impact on property ethics recognition.

Hypothesis 3: Gender will significantly affect recognition of the importance of property ethics issues.

\section{METHODOLOGY}

\section{Questionnaire}

As a part of a broader study, six items were included in a questionnaire to explore recognition of current information technology privacy topics as ethical issues. The specific items were prepared after review of the literature. The first item is Use by others of software or other intellectual property you have created without your consent. This is found in
Calluzzo and Cante (2004) who ask a similar question in their survey "Copying software from the job or school for personal use”. Their question is also similar to the last topic in this survey but this first question personalizes the intellectual property violation to ascertain if individuals are more concerned about use of their intellectual property versus others' intellectual property. Peterson (2002) includes a similar question. Nefarious attacks on network and computer personal property are explored in the next survey items. Development of viruses, worms, and Trojan horses is included as well as Distribution of viruses, worms, and Trojan horses. The remaining factor is Cracking into computers and networks with evil intent. Smith (2004) suggests that "Perhaps the most malicious and dangerous form of hacking has to do with the building and distribution of viruses, worms, and Trojan horses." Webopedia (2004) notes: "Cracking is seen as breaking into a computer system. The term was coined in the mid80 s by hackers who wanted to differentiate themselves from individuals whose sole purpose is to sneak through security systems. Whereas crackers sole aim is to break into secure systems, hackers are more interested in gaining knowledge about computer systems and possibly using this knowledge for playful pranks." Piscatello (2004) notes "For our purposes, we'll expand the definition of cracker found in the Jargon Dictionary to "one who breaks security on a system or network or application". Cracking typically involves writing software specifically designed to discover and exploit flaws in someone else's software.

This survey utilized short statements similar to Calluzzo and Cante (2002) and Kini, Ramakrishna, and Vijayaraman (2004). The length of scenarios only allows for a few ethical situations. And the specific content endemic to ethical scenarios limit the generalizations that can be made. According to Rest, Edwards, and Thoma (1997) short statements tend to have less bias than "longer orations".

The six item survey is presented in Table 1

Table 1. Property ethics issues

\begin{tabular}{|l|}
\hline $\begin{array}{l}\text { Use by others of software or other intellectual } \\
\text { property you have created without your consent }\end{array}$ \\
\hline Development of Viruses, worms, and Trojan horses \\
\hline Hacking without evil intent \\
\hline Cracking with evil intent \\
\hline Distribution of Viruses, Worms, and Trojan horses \\
\hline $\begin{array}{l}\text { Making copies of someone else's software for your } \\
\text { personal use }\end{array}$ \\
\hline
\end{tabular}

An online questionnaire was developed and tested to explore recognition of these current information 
technology topics as ethical issues. Included in the survey were the six items previously noted as property topics. Similar to Loch and Conger (1996), ethical statements were generally personalized for the study. The anonymous responses to the statements relate directly to how the individual views the ethical statement.

The questionnaire was developed as an online survey and sent to several listservs including

- Information Resources Management Association (IRMA)

- Two Major University Faculty/staff listserv

The survey was also conducted in the author's undergraduate classes. Response rates ranged from $100 \%$ in the author's classes to approximately 10 $30 \%$ of the respective faculty/staff listservs, and less than 5\% from the IRMA listserv. All surveys had high response rates except the IRMA listserv. Caution is thus appropriate in the results relating to this subsegment. All analyses were performed using SPSS 10.0.5.

\section{Respondents}

Overall 224 responses were received with 219 valid. Some survey questions had slightly less participation due to non-response on specific questions. A broad cross section of age groups was included, from 40 at 18-24 all the way to 67 at 41-50. Overall, the average age is approximately 41 . The gender mix was about 2 to 1 male to female but this mirrors the IT professional and student mix of male majority. Only $27 \%$ of the sample was students with the largest group being faculty and staff. This reflects the response rate of the survey based on the listservs.

\section{RESULTS}

Hypothesis 1: Information technology property ethical issues will viewed as important ethical issues.

Table 2 present the overall results of the "property" statement survey and the relative importance placed on each topic with regard to whether or not it was recognized as an ethical issue. The issue that received the highest importance was Distribution of viruses, worms, and Trojan horses. With a 3.89 rating nearly everyone recognized how important this issue is to property ethics. This issue was closely followed by its companion issue, Development of viruses etc. Cracking with evil intent was noted as a key ethical issue with a rating of 3.78. The fourth item, Use of software or other intellectual property you have created without your consent was seen as very important ethical issue at 3.6. Finally, Hacking and Use of others' software were seen as lower on the list but still somewhat important at 3.33 and 3.17 respectively.

The first hypothesis was that currently information technology property issues are viewed as important ethical issues. A review of each of the questions exploring current information technology property issues resulted in averages above somewhat important. Dispersion was also somewhat limited around the mean as noted by the standard deviations. As a result, hypothesis one was supported. Information technology property ethics issues are currently viewed as important ethical issues.

Table 2. Overall Survey Descriptive Statistics

\begin{tabular}{|l|r|r|r|r|r|}
\hline & $\mathrm{N}$ & Minimum & Maximum & Mean & Std. Deviation \\
\hline Unauthorized Use of Your IP & 216 & .00 & 4.00 & 3.5926 & .7899 \\
\hline Development of Viruses & 214 & .00 & 4.00 & 3.8364 & .5785 \\
\hline Hacking & 217 & .00 & 4.00 & 3.3318 & .8392 \\
\hline Cracking with Evil Intent & 214 & .00 & 4.00 & 3.7757 & .7161 \\
\hline Distribution of Viruses & 215 & .00 & 4.00 & 3.8884 & .5175 \\
\hline Copying Others' Software & 214 & .00 & 4.00 & 3.1682 & .9689 \\
\hline
\end{tabular}

Hypothesis 2: Age will significantly affect recognition of the importance of property ethics issues.

A series of hypotheses were tested to determine demographic variances in the IT property ethics issues. A preliminary review of the distributions of the responses suggested that the distributions were non-normal. As a result, the non-parametric KruskalWallis Test was used to determine significance of difference among the demographic groups. Kruskal-
Wallis test is a "nonparametric equivalent to one-way ANOVA. Tests whether several independent samples are from the same population. Assumes that the underlying variable has a continuous distribution, and requires an ordinal level of measurement." (SPSS, 1999)

In the past, age has been shown to be a significant factor in ethical decision making. In this study, ranking of importance of Cracking with evil intent, Distribution of viruses, and Copying others' software 
were significantly different among age categories (p $<$.05) (Table 3) and generally directly increased with age. This confirms a similar finding of Vitell (2003) that suggested older individuals more readily follow ethical norms. Hacking, Use of your IP, and Development of Viruses showed no such age difference. This supports Glover, Bumpus, Logan, and Ciesla (1997) who found that age was not a factor in recognition of ethical issues. Overall hypothesis two was partly supported. Age significantly affected three of the six ethical property issues.

Table 3. Significance Levels of Demographic Analyses

\begin{tabular}{|l|l|l|}
\hline & Age & Gender \\
\hline Unauthorized Use of Your IP & 0.379 & 0.139 \\
\hline Development of Viruses & 0.397 & 0.149 \\
\hline Hacking & 0.149 & 0.919 \\
\hline Cracking with Evil Intent & 0.047 & 0.344 \\
\hline Distribution of Viruses & 0.001 & 0.345 \\
\hline Copying Others' Software & 0.000 & 0.002 \\
\hline
\end{tabular}

Hypothesis 3: Gender will significantly affect recognition of the importance of property ethics issues.

Significance levels based on gender are also displayed in table 3 . This study found that five of the six property issues did not show a gender difference. According to this study, females had a higher recognition of Copying others' software than males. This was significant at $\mathrm{p}<.05$. This supports Krete and Cronan (1998) who found in all their information technology ethical scenarios that men were "less likely to consider a behavior as unethical”. Vitell (2003) suggests ethics relationships with gender are "not definitive at this point." Athey (1993) also tested gender differences in determining ethical decisions. Her results did not show significant differences in gender. Hypothesis three was generally rejected. Gender did not significantly affect recognition of property ethical issues with the one exception of Copying others' software.

\section{LIMITATIONS, DISCUSSION, AND CONCLUSION}

The study provides interesting and useful results but as with any study there are limitations that must be recognized. The sample was drawn from a convenience population of students, faculty, and practitioners and may not be applicable to the population as a whole. More extensive and varied sampling would be necessary to verify results. This study should be rightly viewed as the start of an exploration of specific information property issues and can be extended.

Though there have been many past studies that have examined intellectual property and others that have reviewed demographic differences in ethical judgments, this is the first study that examines a range of information age property issues both real and intangible. It is also the first to then study demographic difference within information technology property ethics. Calluzzo and Cante (2004) called for further study of ethics in information technology to "define and clarify the issues, which in turn can form the basis for programs to rectify or at least ameliorate the situation.” This work has explored information technology ethics in several ways. First, the work analyzes whether information technology property is viewed by individuals as an ethical topic. Second the study is the first to consider and analyze property in a multidimensional fashion. Finally, demographic differences were explored. Significant differences were found in many cases between demographic groups based on property issues. These findings can be used to target and address ethical education and enforcement to reduce information technology property losses.

In order to improve IT ethical decision making, Loch and Conger (1996) propose clear corporate definition of acceptable behavior and norms. They also suggest specific policies and guidelines, and corporate ethical training. This should increase ethical computing among employees. Specific IT property ethical behavior should be defined, promulgated, and enforced. Peterson (2002, p.346) has suggested that "identifying factors that contribute to unethical behavior and developing methods of controlling inappropriate behavior in organizations is an area of increasing interest to academicians and practitioners." This paper provides insight into the ethical positions of students, employees, and future IT employees. It was found that gender held little significance in views towards intellectual property ethical issues. To control inappropriate behavior in organizations, efforts should generally be targeted at all individuals regardless of gender. Copying others' software however was shown to be significantly related to gender. More efforts should be placed on education and training and rule enforcement for male employees. Age was also shown to significantly affect attitudes towards intellectual property issues. Programs should more directly target younger employees. This work supports Banerjee, Cronan, 
and Jones (1998) who note the importance of understanding information technology ethical issues due to their potential in the corporate arena for significant security and productivity losses. In order to improve IT ethics, "an overlooked and potentially effective deterrent is the identification of unique and situational characteristics of IS personnel who act ethically/unethically. Identification of unique characteristics could lead to the formulation of more effective ways of solving the problem of unethical use or inappropriate use of computers.” Our study noted some significant demographic influences on information technology ethics. Banerjee, Cronan, and Jones (1998) suggest that methods to improve behavior after identification include education and organizational environment.

This work analyzed the ethics of information technology property. As noted, the complexity of property in an electronic world has created an environment where ethical issues are unclear. The importance of these issues, however, is clear. The United Nations has declared property to be a fundamental right. It is imperative that proper ethical issues be studied and analyzed to clarify current electronic property issues. Rest (1986) suggests that "moral education programs designed to stimulate moral judgment development do produce modest but significant gains". With identification of problem areas, programs can be instituted to improve ethical awareness, education, and enforcement. Further study can to be performed to extend this analysis through the other stages of ethical decision making and identify specific actions to ameliorate the identified ethical dilemmas.

\section{REFERENCES}

1. Athey, S. (1993). A Comparison of Experts' and High Tech Students' Ethical Beliefs In Computer-Related Situations. Journal of Business Ethics. 12(5), 359+.

2. Banerjee, D., Cronan, T., Jones, T. (1998). Modeling IT Ethics: A Study in Situational Ethics. MIS Quarterly. 22(1), 31-60.

3. Bass, K., Barnett, T., and Brown, G. (1999). Individual Difference Variables, Ethical Judgments, and Ethical Behavior Intentions. Business Ethics Quarterly. 9(2), 183-205.

4. Calluzzo V. and Cante C. (2004). Ethics in Information Technology and Software Use. Journal of Business Ethics. 51, 301-312.

5. Commonwealth of Australia (2005). What is Intellectual property? Retrieved March 5,
2005

from

http://www.ipaustralia.gov.au/ip/index.shtml

6. Dean, K. (2005). Focus on Software Piracy Problem. Retrieved March 7, 2005 from http://www.wired.com/news/infostructure/0, 1377,58306,00.html

7. Dorchester County. (2005). Definition of Terms. Retrieved January 13, 2005 from http://www.dorchestercounty.net/ProbateDef . $\mathrm{htm}$

8. Glover, S., Bumpus, M., Logan, J., and Ciesla, J. (1997). Re-examining the Influence of Individual Values on Ethical Decision Making. Journal of Business Ethics. 16, 1319-1329.

9. Gupta, P., Gould, S., Pola, B. (2004). To Pirate or Not to Pirate: A Comparative Study of the Ethical Versus Other Influences on the Consumers Software AcquisitionMode Decision. Journal of Business Ethics. 55(3), 255-274.

10. Harrington, S. (1997). A Test of a Person Issue Contingent Model of Ethical Decision Making in Organizations. Journal of Business Ethics. 16, 363-375.

11. Hay, D., Larres, P., Oyelere, P., and Fisher, A. (2001). The Ethical Perception of Undergraduate Students in ComputerRelated Situations: An Analysis of the Effects of Culture, Gender, and Prior Education. Teaching Business Ethics, 8, 331-356.

12. Jones, T. (1991). Ethical Decision Making by Individuals in Organizations: An IssueContingent Model. The Academy of Management Review. 16(2), 366-395.

13. Kini, R., Ramakrishna, H., and Vijayaraman, B. (2004). Shaping of Moral Intensity Regarding Software Piracy: A Comparison Between Thailand and U.S. Students. Journal of Business Ethics. 49(1), 91-104.

14. Kini, R., Rominger, A., and Vijayaraman, B. (2000). An Empirical Study of Software Piracy and Moral Intensity Among University Students. Journal of Computer Information Systems. 40(3), 62-72.

15. Krete, J. and Cronan, T. (1998). How Men and Women View Ethics. Communications of the ACM. 41(9), 70-76.

16. Laudon, K. (1995). Ethical concepts and information technology. Communications of the ACM. 38(12), 33-39 
17. Loch, K. and Conger, S. (1996). Evaluating Ethical Decision Making and Computer Use. Communications of the ACM. 39(7), 74-83.

18. Oz, E. (2001). Organizational Commitment and Ethical Behavior: An Empirical Study of Information System Professionals. Journal of Business Ethics. 34, 137-142.

19. Peterson, D. (2002). Computer Ethics: The Influence of Guidelines and Universal Moral Beliefs. Information Technology \& People. 15(4), 346-361.

20. Piscatello, D. (2004). Ethical Hacking Could Be So Much More Than An Oxymoron. Retrieved January 24, 2005 from http://hhi.corecom.com/ethicalhacking.htm

21. Rest, J. (1986). Moral Development : Advances In Research and Theory. New York: Praeger.

22. Rest, J., Thoma, S., and Edwards, L. (1997). Designing and Validating a Measure of Moral Judgment: Stage Preference and Stage Consistency Approaches. Journal of Educational Psychology. 89(1), 5-28.

23. Sigma-Mugan, C., Daly, B. Onkal, D. and Kavut, L. (2005). The Influence of Nationality and Gender on Ethical Sensitivity: An Application of the IssueContingent Model. Journal of Business Ethics. 57, 139-159.

24. Smith, D. (2004). Hackers and Hacking. Retrieved December 18, 2004 from http://www.ed2go.com/news/hack.html

25. Smith, H. and Hasnas, J. (1999). Ethics and Information Systems: The Corporate Domain. MIS Quarterly. 23(1), 109-127.

26. SPSS (1999). SPSS Help.

27. Sweeney, J. and Roberts, R. (1997). Cognitive Moral Development and Auditor Independence. Accounting, Organizations, and Society. 22(3/4), 337-352.

28. United Nations General Assembly. (1948). Universal Declaration of Human Rights. Retrieved February 5, 2005 from http://www.un.org/Overview/rights.html

29. Vitell. S. (2003). Consumer Ethics Research: Review, Synthesis and Suggestions for the Future. Journal of Business Ethics. 43, 33-47.

30. Webopedia (2004). Crack. Retrieved December 18, 2004 from http://www.webopedia.com/TERM/C/crack. html

31. Yuthas, K. and Dillard, J. (1999). Ethical Development of Advanced Technology: A Postmodern Stakeholder Perspective. Journal of Business Ethics. 19, 35-49. 